\title{
Desenvolvimento rural da região dos Caminhos de Pedra, no município de Bento Gonçalves/RS - Brasil
}

\author{
Camile Bonotto ${ }^{1}$ \\ Eurico de Oliveira Santos ${ }^{2}$ \\ Humberto Thome-Ortiz ${ }^{3}$ \\ Noe Antonio Aguirre González ${ }^{4}$
}

\begin{abstract}
Resumo
O roteiro pertinente a este estudo está localizado no interior do município de Bento Gonçalves, na Serra Gaúcha, e trata-se de um dos maiores projetos de desenvolvimento pessoal e material existente no Estado do Rio Grande do Sul, local de imigração italiana e que mantém fortes traços dessa cultura. A partir disso, o presente estudo pergunta-se que problemas trouxe o desenvolvimento do turismo no espaço rural da região dos Caminhos de Pedra, em Bento Gonçalves/RS - Brasil? A partir da questão-problema, cria-se o objetivo geral, que consiste em identificar quais os problemas trazidos pelo desenvolvimento do turismo no espaço rural da região dos Caminhos de Pedra: Bento Gonçalves/RS - Brasil. A metodologia pertinente à pesquisa consiste em uma pesquisa de campo, exploratória, quantitativa e qualitativa, utilizando, para o levantamento de dados, entrevistas com os donos das atrações locais. Diante dos dados colhidos, foram identificados os seguintes problemas, ocasionados pelo desenvolvimento do turismo no espaço rural da região dos Caminhos de Pedra: degradação do meio ambiente e especulação imobiliária.
\end{abstract}

Palavras-chave: Problemas. Desenvolvimento. Turismo rural. Caminhos de Pedra. Bento Gonçalves.

\section{Resumen}

La ruta analizada para el desarrollo del presente estudio se encuentra dentro del municipio de Bento Gonçalves y forma parte de la región denominada Serra Gaúcha. Es uno de los mayores proyectos de desarrollo humano y material existente en el Estado de Rio Grande do Sul, lugar de evidente inmigración italiana, lo que mantiene fuertes vestigios de esta influencia cultural. La pregunta de investigación que oriento este estudio es: ¿qué aspectos originan el desarrollo del turismo en las zonas rurales de la región Caminhos de Pedra: Bento Gonçalves RS- Brasil? De la pregunta de investigación deriva el objetivo general, que consiste en: identificar cúales son los problemas que trajo el desarrollo del turismo en las zonas rurales de la región Caminhos de Perda: Bento Gonçalves RS- Brasil. La metodología de investigación consiste en: investigación de campo, exploratoria, cuantitativa, cualitativa y usando para la recolección de datos, a través de entrevistas con los dueños de las atracciones locales. Fueron identificados los siguientes problemas planteados por el desarrollo del turismo en las zonas rurales de la región Caminhos de Pedra: degradación del medio ambiente y especulación inmobiliaria.

Palabras-clave: Problemas. Desarrollo. Turismo Rural. Caminhos de Pedra. Bento Gonçalves.

\footnotetext{
${ }^{1}$ Mestre em Turismo. Centro Superior de Tecnologia TEC BRASIL. camileconotto@gmail.com

${ }^{2}$ Doutor em Ciências Agropecuárias e Recursos Naturais (Universidad Autonoma del Estado de Mexico). Pós-Doutor pela Universidad Autonoma del Estado de México (2017-2016). Pós-Doutor pela Universidade de Aveiro (20122011). Professor da Universidade de Caxias do Sul. eurico58@terra.br

${ }^{3}$ Doutor em Ciencias Agrarias. Presidente de la Fundación Mexicana para el Turismo Rural. Professor da Universidad Autónoma del Estado de México. humbertothome@hotmail.com

${ }^{4}$ Doutor em Ciencias Agropecuarias y Recursos Naturales. Pesquisador do Instituto de Investigación y Capacitación Agropecuaria, Acuícola y Forestal del Estado de México. Professor da Universidad Autónoma del Estado de México. geog_naguirre@yahoo.com.mx
} 


\section{Introdução}

O roteiro-tema do estudo em análise foi idealizado pelo Eng. Tarcísio Vasco Michelon e pelo Arq. Júlio Posenato, visando resgatar, preservar e dinamizar a cultura que os imigrantes italianos trouxeram para a serra gaúcha a partir de 1875 . O roteiro turístico passou a ser concebido quando da realização de um levantamento do acervo arquitetônico de todo o interior do município de Bento Gonçalves, ocorrido no ano de 1987. Constatou-se, então, que a Linha Palmeiro ${ }^{5}$ e parte da Linha Pedro Salgado, áreas abrangidas basicamente pelo Distrito de São Pedro6, composto por sete comunidades (São Pedro, São Miguel, Barracão, São José da Busa, Cruzeiro, Santo Antônio e Santo Antoninho) possuíam o maior acervo de casas antigas, conservando sua cultura e história, com acesso fácil e, consequentemente, um grande potencial turístico, apesar da decadência e do abandono por que vinha passando desde a década de 1970 com a mudança de traçado da rodovia que ligava Porto Alegre ${ }^{7}$ ao norte do estado. Esse precioso acervo material, parcialmente abandonado e esquecido, exigia uma ação rápida para não ter a mesma sorte de tantas e tantas casas de pedra, madeira e alvenaria que acabaram ruindo, ou sendo demolidas. Assim, as primeiras quatro casas foram restauradas e passaram a receber visitação, e outras tiveram obras emergenciais (CAMINHOS DE PEDRA, 2014).

O primeiro grupo de turistas, proveniente do Estado de São Paulo ${ }^{8}$, através da Operadora de Turismo CVC, foi recebido na Casa Merlo, Casa Bertarello, Ferraria Ferri e Cantina Strapazzon ${ }^{9}$ em 30 de maio de 1992. Quando formulado no ano 1992, o Caminhos de Pedra possuía quatro pontos de visitação, sendo eles a Cantina Strapazzon, Ferraria Ferri,

\footnotetext{
${ }^{5}$ A linha Palmeiro localiza-se no interior da cidade de Bento Gonçalves, mais especificamente, no Estado do Rio Grande do sul. Linha também pode ser entendida como uma faixa de terra pertencente ao Distrito de São Pedro (CAMINHOS DE PEDRA, 2014).

${ }^{6}$ Distrito é uma subdivisão de um município (DICIONÁRIO INFORMAL, 2014). É no Distrito de São Pedro que se localiza o roteiro turístico Caminhos de Pedra (CAMINHOS DE PEDRA, 2014).

${ }^{7}$ Porto Alegre possui uma localização privilegiada. Ponto estratégico dentro do Mercosul, é centro geográfico das principais rotas do Cone Sul, equidistante tanto de Buenos Aires e de Montevidéu, quanto de São Paulo e do Rio de Janeiro. Para quem chega às terras gaúchas, Porto Alegre é a porta de entrada do Estado do Rio Grande do Sul para os principais atrativos turísticos da região. A capital dos gaúchos está interligada às rodovias federais BR-290 e BR-116, permitindo a conexão com os demais estados brasileiros e também com o Uruguai e a Argentina (PORTO ALEGRE, 2014). Ficando a uma distância de 121 km de Bento Gonçalves/RS (DISTÂNCIA CIDADES, 2014).

8 São Paulo é uma das 27 unidades federativas do Brasil. O Estado está localizado no sul da região Sudeste e tem como limites os estados de Minas Gerais (N e NE), Rio de Janeiro (NE), oceano Atlântico (L), Paraná (S) e Mato Grosso do Sul (O). Ocupa uma área de $248.808,8$ quilômetros quadrados, sendo pouco maior que o Reino Unido. Sua capital é a cidade de São Paulo (SÃO PAULO, 2014).

${ }^{9}$ Pontos para visitação pertencentes ao roteiro turístico Caminhos de Pedra (CAMINHOS DE PEDRA, 2014).
} 
Casa Bertarello e Casa Merlo. Passados 22 anos, atualmente o roteiro Caminhos de Pedra é composto por dezenove pontos de visitação: Casa Predebom, Casa Righesso, Restaurante Nona Ludia, Atelier João Bez Batti, Casa do Tomate, Foto à Modo Antiga, Pousada Cantelli, Casa da Ovelha, Casa das Massas e Artesanato, Casa Fracalossi, Casa Tecelagem, Restaurante Casa Vanni, Casa das Pequenas Frutas, Cantina Strapazzon, Vinícola Salvati \& Sirena, Vitiaceri Uvas, Casa da Erva-Mate, Casa da Confecção e Lovara Vinhos Finos.

Analisando o desenvolvimento ocorrido nesse roteiro turístico, é pertinente perguntar-se que problemas trouxe o desenvolvimento do turismo no espaço rural da região Caminhos de Pedra ${ }^{10}$ : Bento Gonçalves-RS, surgindo, a partir desse questionamento, o objetivo geral da presente pesquisa: identificar os problemas trazidos pelo desenvolvimento do turismo no espaço rural da região dos Caminhos de Pedra: Bento Gonçalves/RS. Foram também traçados para o estudo em análise os seguintes objetivos específicos: identificar se houve divisão das propriedades e as alterações paisagísticas presentes no roteiro turístico, visto que, para Fávero (2000), o turismo no espaço rural tem sido apontado como uma alternativa para solucionar os problemas existentes no meio rural, como, por exemplo, o êxodo rural, a escassez de recursos, a sazonalidade das colheitas, entre outros. Por outro lado, as experiências têm mostrado que, quando empregado sem planejamento, sem envolvimento da comunidade, o turismo rural pode acarretar ainda maiores prejuízos a essas localidades, descaracterizando sua cultura, poluindo e degradando o meio ambiente e tornando as propriedades alvo da especulação imobiliária.

\section{Metodologia}

O presente estudo estará embasado na seguinte questão-problema: Que problemas trouxe o desenvolvimento do turismo rural na região dos Caminhos de Pedra: Bento Gonçalves/RS ${ }^{11}$ - Brasil? Procurando responder à indagação mencionada, foi preciso utilizar instrumentos como pesquisa de campo - visando observar o turismo no espaço rural da

\footnotetext{
${ }^{10}$ Localizado próximo à cidade de Bento Gonçalves, o roteiro turístico é composto por uma estrada com casas centenárias de imigrantes italianos, sendo que algumas delas podem ser visitadas. O roteiro turístico, nos últimos anos, tem atraído muito a atenção dos turistas que visitam a serra gaúcha (CAMINHOS DE PEDRA, 2014).

${ }^{11}$ Situada no alto da Serra Gaúcha, no Brasil, Bento Gonçalves é uma cidade de gente acolhedora e de natureza exuberante, que figura entre as dez maiores economias do Rio Grande do Sul. Localizada mais especificamente na Encosta Superior do Nordeste do Rio Grande do Sul, a 124 quilômetros da capital, Porto Alegre, a uma altitude de 618m do nível do mar (BENTO GONÇALVES, 2014).
} 
região dos Caminhos de Pedra. Para Ruiz (1976), a pesquisa de campo é a observação dos fatos tal como ocorrem. Já para Marconi e Lakatos (1992), a pesquisa de campo é uma forma de levantamento de dados no próprio local. E, para o caráter exploratório na pesquisa serão utilizadas entrevistas com residentes locais (donos dos atrativos turísticos), visando responder à questão do problema proposto pelo estudo. Segundo Lakatos e Marconi (2003), a pesquisa exploratória é compreendida como investigações cujo objetivo é a formulação de um problema. Para Gil (2007), a pesquisa exploratória tem como objetivo proporcionar maior familiaridade com o problema.

Foram realizadas entrevistas com quatro donos dos atrativos (residentes), tentando, de alguma forma, desvendar a questão-problema exposta pela pesquisa. De acordo com Rampazzo (2005, p. 110), “A entrevista é um encontro entre duas pessoas a fim de que uma delas obtenha informações a respeito de determinado assunto, mediante uma conversação de natureza profissional".

Segundo Pádua (2004, p. 70):

\begin{abstract}
As entrevistas constituem uma técnica alternativa para se coletar dados não documentados, sobre um determinado tema. Deve-se levar em consideração que a entrevista tem suas limitações; dependendo da técnica a ser adotada, os entrevistados podem não dar as informações de modo preciso ou o entrevistador pode avaliar/julgar/interpretar de forma distorcida as informações obtidas.
\end{abstract}

Será também utilizada a pesquisa qualitativa e quantitativa. No que tange à parte qualitativa, esta servirá para descrever o que foi relatado nas entrevistas e observado na pesquisa de campo realizada no roteiro. Para Neves (1996), a pesquisa qualitativa é um conjunto de diferentes técnicas interpretativas que visa descrever os fenômenos. Segundo Lakatos e Marconi (2003), a pesquisa qualitativa trabalha com crenças, valores e opiniões. Já no que diz respeito ao método quantitativo, este será utilizado para quantificar com precisão as respostas dadas pelos entrevistados. De acordo com Richardson (1999), a pesquisa quantitativa caracteriza-se pelo emprego da quantificação na coleta de dados. Beuren e Raupp (2008) afirmam que a pesquisa quantitativa garante a precisão dos resultados.

Primeiramente, foram elaboradas algumas questões com o objetivo de saber os problemas que o desenvolvimento do turismo no espaço rural causou à região dos Caminhos de Pedra. Posteriormente, foram entrevistados quatro residentes (donos) dos atrativos, no 
dia 28/08/2012, tendo cada entrevista uma duração média de aproximadamente vinte minutos. Após isso, as entrevistas foram gravadas e, em seguida, transcritas e analisadas. Depois de transcritas as entrevistas, foram analisados os seus resultados.

\section{Caminhos de Pedra}

Graças à restauração das casas e à visitação turística, desencadeou-se nas comunidades que compõem o roteiro um movimento cultural que permitiu o surgimento de várias iniciativas, visando preservar não só o patrimônio material, mas também o imaterial. Exemplos dessa vitalidade cultural que palpita em todo o roteiro são a preservação do dialeto "talian" (língua típica dos imigrantes do lugar), a Casa da Memória e os grupos artístico-culturais (dança italiana, flauta doce, banda musical, orquestra de câmara, coro e teatro) que se apresentam em ocasiões especiais, ou por solicitação expressa nos restaurantes do roteiro (CAMINHOS DE PEDRA, 2014).

O fato de concentrar o maior acervo arquitetônico da imigração italiana em meio rural do país e a preocupação com a preservação do patrimônio histórico material e imaterial renderam aos Caminhos de Pedra o qualificativo de "museu vivo". Em 2009, por iniciativa do Departamento Estadual Jerônimo Pizzoloto Güerguen, com o apoio do IPHAE (Instituto de Patrimônio Histórico e Artístico do Estado), foi declarado Patrimônio Histórico e Cultural do Rio Grande do Sul12, pela Lei Estadual 13.177/09, promulgada pela então Governadora Yeda Rorato Crusius (CAMINHOS DE PEDRA, 2014).

$\mathrm{O}$ sucesso do novo roteiro animou tanto os idealizadores quanto a comunidade. Em 10 de julho de 1997, com assessoria do SEBRAE ${ }^{13}$, foi fundada a Associação Caminhos de Pedra, congregando empreendedores e simpatizantes. Montou-se, então, um projeto abrangente que contemplava o resgate de todo o patrimônio cultural, não só o arquitetônico, mas envolvendo língua, folclore, arte, habilidades manuais, etc. Atualmente, a Associação Caminhos de Pedra conta com mais de uma centena de associados, e o projeto, considerado

12 O Rio Grande do Sul é um dos estados pertencentes ao Brasil, e possui 10,7 milhões de habitantes, distribuídos em 496 municípios. A sua capital é Porto Alegre, com 1,4 milhões de habitantes (BRASIL TURISMO, 2014).

13 O SEBRAE (Serviço Brasileiro de Apoio às Micro e Pequenas Empresas) é uma entidade civil sem fins lucrativos e opera como um serviço social autônomo. É uma instituição técnica voltada para o fomento e a difusão de programas que têm como objetivos o fortalecimento e a promoção de micro e pequenas empresas (MPEs). No SEBRAE, o governo e a iniciativa privada atuam em parceria (INFO ESCOLA, 2014). 
pioneiro no Brasil em termos de turismo rural e cultural, está recebendo uma visitação média anual de 60.000 turistas. Diante disso, o roteiro está em expansão e possui dezenove pontos de visitação e 71 pontos de observação externa (CAMINHOS DE PEDRA, 2014).

\section{Turismo}

Jafari (1977) define turismo como o estudo do homem longe de seu habitat. De acordo com Acerenza (1991), o turismo é um fenômeno dos tempos atuais, fruto da crescente necessidade de recuperação e troca de ambiente. Segundo McIntosh e Goeldner (1992), turismo é definido como o somatório dos fenômenos e das relações que surgem da interação dos turistas, empresas e comunidades receptoras no processo de atração desses turistas. De La Torre (1997) define turismo como um fenômeno social que consiste no deslocamento voluntário e temporário de indivíduos ou grupos de pessoas que, fundamentalmente por motivos de recreação, descanso, cultura ou saúde, saem de seu local de residência habitual.

Para Padilla (1994), o turismo é um fenômeno social que consiste no movimento voluntário e temporal de indivíduos ou grupo de pessoas. Barretto (1995) e De La Torre (1997) conceituam turismo como um fenômeno puramente social. De acordo com Beni (2001), a palavra turismo deriva do inglês tourism, ou do francês tour, resultando em inúmeros significados, como viagens de recreio, esporte, negócios, etc.

Barretto (1995, p. 43) fala um pouco mais sobre o conceito de turismo:

O conceito turismo surge no século XVII na Inglaterra, referido a um tipo especial de viagem. A palavra tour é de origem francesa, como muitas palavras do inglês moderno que definem conceitos ligados à riqueza e à classe privilegiada. [...] a palavra tour quer dizer volta e tem seu equivalente no inglês turn, e no latim tornare.

Segundo Ansarah (2000), as pessoas são motivadas a fazer turismo por inúmeras razões, como a ilusão de retornar a um período anterior ao que se vive, a busca do bucólico, o retorno à natureza, enfim, a romantização da viagem está ligada tanto à própria sensibilidade na manutenção de um equilíbrio do meio ambiente quanto ao desejo de rompimento do cotidiano. 


\title{
5 Turismo no espaço rural
}

Segundo a Comissão das Comunidades Europeias (1990), o turismo rural não compreende somente férias nas quintas, mas também qualquer outra atividade no campo. É compreendida como toda atividade turística no interior e atividade turística implantada no meio rural, deixando ampla margem para esse tipo de turismo.

De acordo com a definição de Cals, Capellá e Vaqué (1995, p. 23):

\begin{abstract}
No entanto, é mais apropriado referir-se à globalização dos movimentos turísticos que ocorrem no meio rural com a expressão 'turismo no espaço rural', e reserva o turismo rural para aquelas manifestações que em maior medida se identificam com as especificações da vida rural, seu habitat, sua economia e sua cultura.
\end{abstract}

De acordo com Tulik (1997), as expressões e termos existentes sobre turismo rural variam conforme a realidade de cada país e expressam diferentes maneiras de aproveitar o espaço rural. Roque e Mendonça (1999) conceituam turismo rural como a maneira turística de visitar e conhecer o ambiente rural. Segundo Rodrigues (2000), só se pode caracterizar a atividade como turismo rural quando existir interação com o espaço rural. Para Almeida e Riedl (2000), o turismo rural é uma atividade que ocorre na zona rural juntamente com a pecuária. De acordo com Silveira (2001), o turismo rural é o conjunto de atividades que compõe a vida no campo, envolvendo a experiência do dia a dia nas fazendas. Beni (2002, p. 31) define turismo rural como: "[...] o deslocamento de pessoas para espaços rurais, em roteiros programados ou espontâneos, com ou sem pernoite, para fruição dos cenários e instalações rurícolas".

O Ministério do Turismo (2003) conceitua turismo rural como o conjunto de atividades desenvolvidas no meio rural, comprometidas com a produção agropecuária. Zimmermann (2000) fala que, em virtude das características áreas rurais brasileiras, é comum a multiplicidade de atividades turísticas. Segundo Pinto e Lanzer (2005), o mundo rural não pode mais ser visto apenas pela sua relação com a produção de alimentos para o seu sustento e o da cidade, pois, segundo Sharpley e Jepson (2011), o turismo rural surgiu como uma busca temporária de pessoas por descanso das tensões diárias. Para Kajanus et al. (2004), a cultura é um fator de sucesso para o turismo rural. De acordo com Park e Yoon (2009), 
estudos revelam que os ativos ambientais e a diferenciação do estilo de vida no meio rural fazem com seja uma das principais dimensões para o turismo propiciado por esse meio.

De acordo com Mac Donald e Jolliffe (2003), o turismo rural transformou-se em uma ferramenta de desenvolvimento para áreas rurais isoladas. Para Park et al. (2012), o turismo rural também tem sido reconhecido por sua eficácia em contribuir para o desenvolvimento das áreas rurais. Segundo Liu (2006), zonas rurais têm limitadas opções para o desenvolvimento econômico. Conforme Látková e Vogt (2012), quando as atividades econômicas não são distribuídas igualmente entre os municípios, os moradores que vivem em áreas rurais podem perceber o turismo rural como uma importante fonte econômica. De acordo com Tangeland, Vennesland e Nybakk (2013), o turismo rural é um importante setor de negócios. Para Dudensing et al. (2011), o turismo, em áreas rurais, é de suma importância para o desenvolvimento econômico nos EUA. Segundo Su (2011), o desenvolvimento do turismo rural constituiu-se para a China uma ferramenta eficaz para diversificar a economia e aliviar a pobreza nas zonas rurais.

\section{Análise dos resultados}

No dia $28 / 08 / 2012$, foram realizadas as quatro entrevistas com donos dos atrativos existentes no roteiro turístico Caminhos de Pedra, localizado no município gaúcho de Bento Gonçalves - Rio Grande do Sul, Brasil, objetivando identificar os problemas trazidos pelo desenvolvimento do turismo no espaço rural da região dos Caminhos de Pedra: Bento Gonçalves/RS - Brasil. Nelas foram analisadas duas vertentes: a primeira questão visou desvendar se o atrativo sempre pertenceu à família, e a segunda teve por objetivo descobrir se o residente identificava alterações paisagísticas provocadas pelo desenvolvimento do turismo, e as duas últimas estão relacionadas à cultura da uva e do vinho e ao contato do turista com essas culturas.

O Quadro 1, apresentado na página seguinte, apresenta as respostas dos entrevistados às questões apresentadas. 


\section{Quadro 1 - Respostas dos entrevistados às questões apresentadas}

\begin{tabular}{|c|c|}
\hline \multicolumn{2}{|c|}{ Pergunta 1: A propriedade sempre foi da sua família? } \\
\hline Entrevistado 1 & Não. Nós morávamos na comunidade e compramos aqui. \\
\hline Entrevistado 2 & $\begin{array}{l}\text { Sim. O casarão-sede do negócio ficava do outro lado da rua. Nós o compramos } \\
\text { e o preservamos da destruição. }\end{array}$ \\
\hline Entrevistado 3 & Sempre. Desde os bisavôs. \\
\hline Entrevistado 4 & Sim. \\
\hline \multicolumn{2}{|c|}{ Pergunta 2: Você consegue de alguma forma notar alterações na paisagem do roteiro? } \\
\hline Entrevistado 1 & Continua a mesma não mudou nada. \\
\hline Entrevistado 2 & $\begin{array}{l}\text { No nosso caso, muito. No visual do vale, você encontra plantas invasoras, um } \\
\text { número maior de casas e o próprio asfalto. } \\
\text { Sim, meus pais e meu irmão trabalham com isso ainda desde a época do meu } \\
\text { vô. Eles foram aprendendo com ele e ainda trabalham, até hoje estão } \\
\text { trabalhando, podando os galhos, que agora é época de poda, o que os prende e } \\
\text { forma os brotinhos e fica tudo alinhado direito. Tudo isso mais para a venda, no } \\
\text { caso para vinhos finos. Eles produzem uva para uma grande cooperativa de } \\
\text { Bento Gonçalves. Conforme o pedaço de terra, eles sabem o que melhor dá. }\end{array}$ \\
\hline Entrevistado 3 & Não. \\
\hline Entrevistado 4 & As construções, devido ao progresso do roteiro. \\
\hline \multicolumn{2}{|c|}{ Pergunta 3: É produzido vinho e cultivada uva na propriedade? } \\
\hline Entrevistado 1 & Só uva para consumo próprio. \\
\hline Entrevistado 2 & $\begin{array}{l}\text { Sim, meus pais e meu irmão trabalham com isso ainda desde a época do meu } \\
\text { vô. Eles foram aprendendo com ele e ainda trabalham, até hoje estão } \\
\text { trabalhando, podando os galhos, que agora é época de poda, o que os prende e } \\
\text { forma os brotinhos e fica tudo alinhado direito. Tudo isso mais para a venda, no } \\
\text { caso para vinhos finos. Eles produzem uva para uma grande cooperativa de } \\
\text { Bento Gonçalves. Conforme o pedaço de terra, eles sabem o que melhor dá. }\end{array}$ \\
\hline Entrevistado 3 & $\begin{array}{l}\text { Sim. É produzido vinho colonial, mais para o consumo diário. Este vinho é } \\
\text { proveniente dos pés de uva que os meus bisavôs plantaram. São pés } \\
\text { centenários, que ainda produzem a uva, e a gente elabora o vinho aqui na casa. }\end{array}$ \\
\hline Entrevistado 4 & Não. \\
\hline \multicolumn{2}{|c|}{ Pergunta 4: A cultura da uva e do vinho é repassada para o turista? } \\
\hline Entrevistado 1 & Sim, na safra. Os poucos pés de uva que há, quem come é o próprio visitante \\
\hline Entrevistado 2 & $\begin{array}{l}\text { Não, essa parte não, porque a propriedade é bem extensa. Eu tenho ali fora as } \\
\text { parreiras que são bem pequeninhas, daí, quando tem a época de uva, elas } \\
\text { sempre produzem, e o pessoal acaba comendo. Também vendo uva. Mas } \\
\text { aquelas do meu pai não, porque é bem longe. }\end{array}$ \\
\hline Entrevistado 3 & $\begin{array}{l}\text { Sim. Quando o turista chega na propriedade, ele tem acesso diretamente ao pé } \\
\text { de uva. Agora, nessa época do ano, vem a poda, depois tem a desfolha, vem a } \\
\text { uva já pronta. Aí o turista chega e degusta a uva no pé. Então eles têm acesso a } \\
\text { todas as fases da videira. Desde quando a pessoa chega, a gente acompanha e } \\
\text { conta a história, desde o tempo dos bisavós, que vieram da Itália, que } \\
\text { construíram esta casa e como é feito o vinho aqui. Como era o processo } \\
\text { antigamente e como a gente elabora hoje o vinho. }\end{array}$ \\
\hline Entrevistado 4 & Não. Trabalhamos única e exclusivamente com leite e derivados de leite. \\
\hline
\end{tabular}

Fonte: Os autores. 
A entrevista proporcionou a seguinte análise acerca da questão-problema levantada inicialmente: cerca de $75 \%$ dos entrevistados dizem que o atrativo turístico pertencente ao roteiro Caminhos de Pedra sempre pertenceu a sua família, sendo passado de geração a geração, e apenas $25 \%$ dizem que já moravam na comunidade e acabaram comprando-o. Aproximadamente $50 \%$ dos entrevistados afirmam que o roteiro turístico Caminhos de Pedra provocou alterações paisagísticas, como construções de novas casas (número maior) e outras construções, devido ao seu progresso. Porém os outros $50 \%$ dizem que a paisagem da região nada mudou.

A uva é cultivada na propriedade por $75 \%$ dos entrevistados, um costume passado dos avôs para os netos. Em algumas propriedades, as uvas são revendidas para uma grande cooperativa de Bento Gonçalves; em outras, é produzido um vinho colonial para o consumo diário da família, e em outras ainda, é cultivada uva somente para o consumo próprio. No entanto, $25 \%$ dos entrevistados não cultivam uva em suas propriedades. Dos $75 \%$ dos entrevistados que dizem produzir uva em suas propriedades, apenas 50\% acabam, de alguma forma, repassando a cultura da uva e do vinho para o turista.

Para Santos (2004), o turismo rural não será a solução definitiva para os problemas latentes do setor primário, entretanto poderá se constituir em um adicional nas receitas das propriedades. Percebe-se, assim, que o turismo no espaço rural desenvolvido no roteiro turístico Caminhos de Pedra também auxiliou na redução do êxodo rural, um dos grandes problemas presentes nesse meio. Foi identificado, também, por parte dos autores integrantes deste artigo científico, que o turismo rural propiciou à região do roteiro turístico Caminhos de Pedra uma ferramenta para o desenvolvimento local, assim como tratado pelos autores Mac Donald e Jolliffe (2003), Park, Lee e Joon (2012) e Tangeland, Vennesland e Nybakk (2013).

\section{Considerações finais}

Segundo Mac Donald e Jolliffe (2003), o turismo rural transformou-se em uma ferramenta de desenvolvimento para áreas rurais isoladas. Nos dias atuais, é bem relevante o número de propriedades rurais que incorporam atividades turísticas em suas rotinas, fazendo-se necessárias ações para a estruturação e caracterização da nova propriedade rural. Para melhor entender os problemas que isso também pode causar no espaço em que 
essas atividades estão inseridas, o presente artigo tem por objetivo identificar os problemas trazidos pelo desenvolvimento do turismo no espaço rural da região dos Caminhos de Pedra: Bento Gonçalves/RS - Brasil. Os seguintes pontos serviram para nortear os objetivos específicos da presente pesquisa: identificar se houve divisão de propriedades e alterações paisagísticas no espaço percorrido pelo roteiro turístico. Tal objetivo foi alcançado, conforme ficou evidenciado na análise dos resultados.

Nota-se que cerca de $75 \%$ dos entrevistados dizem que o atrativo turístico visitado no roteiro Caminhos de Pedra sempre pertenceu a sua família, sendo passado de geração a geração, e apenas $25 \%$ dizem que já moravam na comunidade e o acabaram comprando. Aproximadamente $50 \%$ dos entrevistados afirmam que o roteiro turístico Caminhos de Pedra sofreu alterações paisagísticas, como construções de novas casas (número maior) e outras construções, devido ao seu progresso. Entretanto, os outros $50 \%$ dizem que a paisagem da região pertencente ao roteiro nada mudou. Para $75 \%$ dos entrevistados, é cultivada uva na propriedade, passando essa cultura de avôs para netos. Zimmermann (2000) fala que, em virtude das características das áreas rurais brasileiras, é comum a multiplicidade de atividades turísticas. Assim, em algumas propriedades, as uvas são revendidas para uma grande cooperativa de Bento Gonçalves. Em outras, é produzido um vinho colonial para o consumo diário da família, e em outras é cultivada a uva somente para o consumo próprio. Dos $75 \%$ dos entrevistados que dizem produzir uva em suas propriedades, apenas $50 \%$, de alguma forma, acabam repassando a cultura da uva e do vinho para o turista.

Nesse sentido, o presente estudo constatou que o turismo rural no roteiro turístico Caminhos de Pedra não trouxe apenas problemas para a região, mas, também, atuou proativamente como fonte redutora do êxodo rural. De acordo com Pinto e Lanzer (2005), o mundo rural não pode mais ser visto apenas por sua produção de alimentos para o seu sustento e o da cidade. Portanto, o presente estudo revelou como problemas causados pelo desenvolvimento do turismo rural a degradação do meio ambiente e a especulação imobiliária. 


\section{Referências}

ACERENZA, Miguel A. Administración Del Turismo: Conceptualización y organización. México: Trillas, 1991.

ALMEIDA, J. A; RIELD, M. Ecologia, Lazer e Desenvolvimento. Bauru: 2000.

ANSARAH, M. G. R. Turismo: segmentação de mercado. 3. ed. São Paulo: Futura, 2000.

BARRETTO, M. Manual de iniciação ao estudo do turismo. Campinas: Papirus, 1995.

BENI, M. C. Análise Estrutural do turismo. 6. ed. São Paulo: Senac, 2001.

BENI, M. C. Conceituando turismo rural, agroturismo, turismo ecológico e ecoturismo. In: BARRETTO, M.; TAMANINI, E. (Org.). Redescobrindo a ecologia no turismo. Caxias do Sul: EDUCS, 2002.

BENTO GONÇALVES. Conheça a cidade. Disponível em: <http://www.bentogoncalves.rs.gov.br/a-cidade/conheca-a-cidade>. Acesso em: 13 jun. 2014.

BEUREN, I. M.; RAUPP, F. M. Metodologia da Pesquisa Aplicável às Ciências Sociais. In: COLAUTO, R. D.; LONGARAY, A. A.; PORTON, R. A. de B.; RAUPP, F. M.; SOUSA, M. A. B. de; BEUREN, I. M. (Org.). Como Elaborar Trabalhos Monográficos em Contabilidade: teoria e prática. São Paulo: Atlas, 2008.

BRASIL TURISMO. Estado do Rio Grande do Sul. Disponível em: <http://www.brasilturismo.com/rio-grande-sul/estado.htm>. Acesso em: 13 jun. 2014.

CALS, J.; CAPELLÁ, J.; VAQUÉ, E. El turismo e em desarollo rural de Espanha. Madrid: Edita, 1995.

CAMINHOS DE PEDRA. Histórico. Disponível em:

<http://www.caminhosdepedra.org.br/pt/?pg=historico>. Acesso em: 25 mar. 2014.

COMISSÃO EUROPEIA. Para um turismo rural de qualidade: Gestão integrada da qualidade (GIQ) dos destinos turísticos rurais. Direção-Geral da Empresa Unidade de Turismo, Bruxelas, 2000.

DE LA TORRE, Oscar. El Turismo, Fenômeno Social. Cidade do México: Fundo de Cultura Econômico, 1997.

DISTÂNCIA CIDADES. Distância de Porto Alegre a Bento Gonçalves. Disponível em: <http://br.distanciacidades.com/distancia-de-porto-alegre-a-bento-goncalves>. Acesso em: 13 jun. 2014. 
DICIONÁRIO INFORMAL. Distrito. Disponível em:

<http://www.dicionarioinformal.com.br/distrito>. Acesso em: 13 jun. 2014.

DUDENSING, R. M.; HUGHES, D. W.; .SHIELDS, M. Perceptions of tourism promotion and business challenges: A survey-based comparison of tourism businesses and promotion organizations. Tourism Management. v. 32, n. 6, 2011, p. 1453-1462. Disponível em: <http://www.periodicos.capes.gov.br>. Acesso em: 6 jun. 2014.

FÁVERO, Ivane Maria Remus. Diretrizes para o desenvolvimento sustentável do turismo rural. UCS. (Monografia de conclusão - Especialização em gerenciamento do desenvolvimento turístico) - Universidade de Caxias do Sul, 2000. Disponível em:

<http://www.caminhosdepedra.org.br/pdf/Ivane_Remus_Favero-2000.pdf>. Acesso em: 6 jun. 2014.

GIL, A. C. Como elaborar projetos de pesquisa. 4. ed. São Paulo: Atlas, 2007.

INFO ESCOLA. Disponível em: <http://www.infoescola.com/empresas/sebrae-servicobrasileiro-de-apoio-as-micro-e-pequenas-empresas>. Acesso em: 13 jun. 2014.

JAFARI, J. Editor's page. Annals of Tourism Research, 5 (Supplement 1), 1997, p. 6-11.

KAJANUS, M.; KANGAS, J.; KURTTILA, M. The use of value focused thinking and the A'WOT hybrid method in tourism management. Tourism Management. v. 25, n. 4, 2004, p. 499-506. Disponível em: <de http://www.periodicos.capes.gov.br>. Acesso em: 6 jun. 2014.

LÁTKOVÁ, P.; VOGT, C. A. Residents' Attitudes toward Existing and Future Tourism Development in Rural Communities. Journal of Travel Research. v. 51, n. 1, 2012, p. 50-67. Disponível em: <http://www.periodicos.capes.gov.br>. Acesso em: 6 jun. 2014.

LAKATOS, E. M.; MARCONI, M. A. Fundamentos de metodologia científica. 5. ed. São Paulo: Atlas, 2003.

LIU, A. Tourism in rural areas: Kedah, Malaysia. Tourism Management. v. 27, n. 5, 2006, p. 878-889. Disponível em: <http://www.periodicos.capes.gov.br>. Acesso em: 6 jun. 2014.

MACDONALD, R.; JOLLIFFE, L. Cultural rural tourism: Evidence from Canada. Annals of Tourism Research. v. 30, n. 2, 2003, p. 307-322. Disponível em:

<http://www.periodicos.capes.gov.br>. Acesso em: 6 jun. 2014

MARCONI, Marina de Andrade; LAKATOS, Eva Maria. Metodologia do trabalho científico. 4. ed. São Paulo: Atlas, 1992.

MCINTOSH, R. W.; Goeldner, C. R. Tourism Principles, Practices, Philosophies. Ohio: Grid Publishing Inc. John Wiley e Sons, Columbus, 1992. 
MINISTÉRIO DO TURISMO. Diretrizes para o desenvolvimento do turismo rural no Brasil (2003-2007). Brasília, 2003. Disponível em:

<http://www.mda.gov.br/saf/arquivos/diretrizes.pdf>. Acesso em: 17 maio 2014.

NEVES, J. L. Pesquisa qualitativa: características, usos e possibilidades. Caderno de pesquisa em administração, v. 1., n. 3, 2006.

PADILLA, O. de La T. El Turismo: Fenómeno Social. Sección de Obras de Sociologia. México: Fondo de Cultura Económica, 1994.

PÁDUA, Elisabete Matallo Marchesini de. Metodologia da pesquisa: Abordagem teóricoprática. 10 ed. rev. e atual. Campinas: Papirus, 2004.

PARK, D.-B.; YOON, Y.-S. Segmentation by motivation in rural tourism: A Korean case study. Tourism Management. V. 30, n 1, 2009, p. 99-108. Disponível em:

<http://www.periodicos.capes.gov.br>. Acesso: 6 jun. 2014.

PARK, D.-B.; LEE, H.-J; JOON, Y.-S. Understanding the Benefit Sought by Rural Tourists and Accommodation Preferences: A South Korea Case. International Journal of Tourism Research, 2012. Disponível em: <http://www.periodicos.capes.gov.br>. Acesso em: 6 jun. 2014.

PINTO, Rodrigo B. \& LANZER, Rosane. Turismo no espaço rural: delimitando tendências. In: BARRETTO, Margarita (Org.). Anuário de pesquisa do programa de mestrado em turismo. Caxias do Sul: EDUCS, 2005.

PORTO ALEGRE. Turismo. Disponível em:

<http://www2.portoalegre.rs.gov.br/turismo/default.php?p_secao=257>. Acesso em: 13 jun. 2014

RAMPAZZO, Lino. Metodologia cientifica: para alunos dos cursos de graduação e pósgraduação. 3. ed. São Paulo: Loyola, 2005.

RICHARDSON, Roberto Jarry e Colaboradores. Pesquisa social: métodos e técnicas. São Paulo: Atlas. 1999.

RODRIGUES, Ivone da Silva. As abordagens tipológicas envolvendo o turismo no espaço rural. II Congresso Brasileiro de Turismo Rural: Turismo, novo caminho no espaço rural brasileiro. Anais. Piracicaba: FEALQ, 2000.

ROQUE, Andréia M; MENDONÇA, Maria Cristina. A. Bases para a produção do turismo no espaço rural. In: CONGRESSO BRASILEIRO DE TURISMO RURAL. Piracicaba: FEALQ, 1999.

RUIZ, J. A. Metodologia científica: guia para eficiência nos estudos. In: SILVEIRA, Marcos. Política de Turismo: oportunidades ao Desenvolvimento local. São Paulo, 1976.

SANTOS, Eurico de Oliveira. O agroturismo e o turismo rural em propriedades da metade sul do Estado do Rio Grande do Sul. Porto Alegre: Pallotti, 2004. 
SÃO PAULO. Conheça. Disponível em:

<http://www.saopaulo.sp.gov.br/conhecasp/principal_conheca>. Acesso em: 13 jun. 2014

SHARPLEY, R; JEPSON, D. Rural tourism: A spiritual experience? Annals of Tourism Research. v. 38(1), 2011, p. 52-71. Disponível em: http://www.periodicos.capes.gov.br>. Acesso em: 6 jun. 2014.

SU, B. Rural tourism in China. Tourism Management. v. 32(6), 2011, p. 1438-1441. Disponível em: http://www.periodicos.capes.gov.br>. Acesso em: 6 jun. 2014.

TANGELAND, T.; VENNESLAND, B; NYBAKK, E. Second-home owners' intention to purchase nature-based tourism activity products: A Norwegian case study. Tourism Management. v. 36, 2013, p. 364-376. Disponível em: <http://www.periodicos.capes.gov.br>. Acesso em: 6 jun. 2014.

TULIK, Olga. Do conceito às estratégias para o desenvolvimento do turismo rural. In: RODRIGUES, Adyr Balastre (Org.). Turismo e Desenvolvimento Local. São Paulo: Hucitec, 1997.

ZIMMERMANN, A. Planejamento e organização do turismo rural no Brasil. In: ALMEIDA, Joaquim Anécio; FROEHLICH, José Marcos; RIEDL, Mário (Orgs.). Turismo rural e desenvolvimento sustentável. Campinas: Papirus, 2000. 